\title{
Analysis on Cause and Influence of International Economic Situation on Financial Crisis
}

\author{
Xinru Wang \\ College of Finance and Economics, Guangzhou Panyu Polytechnic, Guangzhou 511483, China
}

Keywords: International economic situation; Financial crisis; Cause analysis

\begin{abstract}
The international financial crisis poses strong impacts on the economy of countries all over the world and global ideology, culture and other fields. The crisis reveals the further intensification of basic contradictions of capitalist society. Countries all over the world conduct reflection and adjustment driven by the financial crisis. The international economic situation imposes important influences on the international financial crisis, which is embodied as European Debt Crisis and "Wall Street". By analyzing the cause and influence of international economic situation on the financial crisis, the influence of financial crisis on China's development is studied and the solution is presented.
\end{abstract}

\section{Introduction}

Eight years have passed since the outbreak of subprime mortgage loan in 2007. Countries all over the world are making up for the consequence of financial crisis pertinently. In view of the cause of the financial crisis, the international economic circle points to US because they think the international financial crisis is caused by the overdraft consumption, week regulation, political deficiency and other comprehensive factors of the United States. However, in the analysis of financial crisis, attention should not be paid to the appearance, but the basic contradictions of international financial crisis, which requires to analyze the cause of financial crisis from the basic contradiction and economic system deficiency ain the capitalist mode of production. From the influence of international economic situation on the financial crisis, the cause and influences are further studied in this paper.

\section{Overview of financial crisis}

\section{Economic analysis of financial crisis}

The New PalgraveA Dictionary of Economics defines the financial crisis as follows: most financial indicators, including assets, price and bankruptcy, are closed down or have superperiod deterioration.

Main cause of financial crisis

(1) Financial capital market

Short-term currency market factor is the main symbol of periodical outbreak of financial crisis and the decline of interest rate may lead to continuous increase of domestic relevant investment so as to cause the sharp increase of currency in circulation in the market. However, due to the decline of interest rate, the investment growth cannot be controlled, thus making the capital continuously flow to the financial market driven by the interest to cause bubble growth, which may aggravate the risk of the outbreak of financial crisis.

(2) Stock market

Stock also has direct influences on the financial crisis. In the previous financial crisis, the influence of stock market is the most direct and significant. The rapid development of science and technology promotes the prosperity of stock market, but also brings certain hidden troubles to the financial crisis. 


\section{Real estate market}

Real estate market is the major battlefield of financial crisis, so does this financial crisis. Due to the continuous rise of price in the real estate market, the Federal Reserve implements low-interest rate housing policy to reduce the mortgage cost so as to make massive capital flow to the real estate market. Therefore, the financial crisis first breaks out in the real estate market.

Financial innovation. In the financial crisis, the function of financial derivative and instrument should not be ignored. The housing mortgage bond, asset backed mortgage rights, related mainstream trade products are not included in the assets and liabilities mortgage statement. However, it should be noted that the house alone is still the important basic content of securitized assets. Therefore, the financial market suffers a serious blow in the house loan market under the condition of interest-based adjustment and the financial crisis is hair-trigger.

\section{Important performance of financial crisis}

In 2007, the second largest subprime mortgage company of the United Sates applied to and declared bankruptcy, thus leading to the widespread outbreak of financial crisis. The unstable factors hidden in the real estate market of the United States with strong trend development broke out, which further promoted the asset bubble. The influences caused by the financial crisis were: first, the international financial crisis led to the sharp decline of global stock market so that many important investment institutions all over the world were bankrupt; second, financial institutions in the world suffered a great impact and their total value was dwindled, thus aggravating the economic deterioration; third, the financial economic pattern of the United States was changed and the government further enhanced the regulation on investment bank; fourth, financial crisis further impacted the development of real economy, leading to the low development of real economy; fifth, the development of real economy was shocked and the international trade partners were reduced, thus causing serious barriers to the economic development of other countries all over the world.

\section{Analysis of the formation mechanism of financial crisis}

\section{Analysis of the main cause of financial crisis}

\section{Financial crisis}

The economic crisis is a further extension of financial crisis, in which the currency acts as the payment mode, indicating that the crisis is transformed into the currency crisis. The essential cause for the crisis is the unbalance between production and consumption. The limited consumption ability of consumers and product surplus in the capital market will lead to the crisis.

\section{Conditions of crisis}

(1) Capital accumulation

Facing the complex and fierce market competition, the capital should be accumulated to get profits, which can reduce the profit ratio of capital, thus leading to the further decrease of profit and promoting the next round of capital accumulation. This requires to stop the accumulation by crisis.

(2) Credit development

The capital market gets supernormal profit by capital accumulation. However, restricted by the enterprise accumulation, enterprise should complete the capital accumulation by commercial bank and other financial institutions. This credit finance situation further brings some hidden troubles to the financial crisis of capitalism. Finally, it leads to the fictitious needs caused by credit and cannot meet the conflicting need between production and consumption.

\section{Analysis of the eruptive cycle and spreading form of financial crisis}

\section{Cyclic features of financial crisis}

The basic contradictions under the capitalism cannot be reconciled, thus leading to the cyclic financial crisis. The time of cyclic financial crisis is associated with the capitalist reproduction conditions, which poses direct influences on the length of financial crisis cycle. With the rapid 
development of economy, science and technology all over the world, the average update time of fixed assets is shortened, thus leading to the decrease of financial cycle.

Spreading of financial crisis

Financial crisis generally breaks out in a country and then spreads to other countries and finally affect countries all over the world. In the international trade, the application degree and width of credit capital and fictitious capital have been improved continuously and the capital accumulation among countries has beyond the territorial limitation. In this process, the outbreak of financial crisis of a country will impose far-reaching financial currency crisis influences on the associated trade cooperation countries.

\section{Analysis of cause and influence of international economic situation on financial crisis}

\section{Analysis from economic theory}

Institutional level

The main cause for subprime crisis is caused by the loose economic policy of the United States essentially due to its political, economic and institutional environment. In the liberalism market economy, the government has insufficient economic regulation ability and the loose policy of financial regulation causes the liberal operation of financial capital.

Political level

The main cause at the political level lies in the long-term low interest rate and relatively loose national currency policy of the United States. In the coordination development process between real economy and fictitious economy, the balance relationship is not controlled well and even there is development disconnection, thus giving rise to the subprime crisis.

Market level

It is found by analyzing the cause at the market level that it is the most direct reason for the financial crisis from the micro perspective. As the excessive development of financial market makes the capital flow and utilization exceed the market carrying ability, plus the relatively loose low-interest policy of the United States, the subprime crisis breaks out.

Crisis cycle level

As an important factor that affects the financial crisis, the cyclic factor cannot be ignored because it is the most direct influencing factor that reflects the cyclic change of global economy. The economic activities have their own laws and will expand or contract towards the economic development direction and market law direction. In 2001, the United States experienced a period of economic prosperity, but must enter a frozen or depression period after the peak of market prosperity.

\section{Cause analysis based on Marxism theory}

Basic contradiction of capitalism

The subprime crisis is resulted from the economic crisis of capitalist world due to the cyclic crisis caused by the capital overproduction and also the overproduction crisis caused by the credit expansion. The essential cause of this subprime crisis lies in the basic contradiction of capitalism.

Fictitious economic growth

(1) Liquidity

The Federal Reserve finally controls the economic setback since 2001 after 11 interest reductions and adjusts the fund date as $1 \%$. This method of reducing the interest rate promotes the economic consumption behavior of the United States to give rise to the excessive consumption so as to cause the unbalance between economic growth and development. Therefore, American government insists on promoting the low interest rate policies, thus leading to the economic bubble.

(2) Many subprime mortgages

The United States continuously promotes the low interest rate policies to guide the market capital flow and improves the housing price based on this to further stimulate the house loan consumption. The financial institution can meet the needs of house loan market and grab profits through this market. 
The United States enters a low-interest rate economic development era since 2001 and the subprime loan development finds a new breakthrough to promote the economic development in a short time. The average annual growth was about $38 \%$, which brings hidden troubles to the financial crisis.

(3) Over development of financial innovation

The commercial banks and other relevant financial institutions may ignore the risk control and make use of the high leverage profit mode of investment bank driven by interests. Wall Street forms multi-class financial derivatives by assets securitization with the financial instrument to get profits. Lacking of financial control

(1) Uncontrolled government regulation

The rapid development of social economy makes the government excessively believe in the market and rely on the market regulation ability in the process. Therefore, the external regulation is weaker and weaker. This extreme management concept is obvious in the American market and its influences expand continuously. The external regulation can reduce the development efficiency of market economy to a certain degree, accompanied with many risk hazards, which is the attitude towards the external supervision in the American market theory. Considering the massive financial products, American Government takes corresponding policies, modifies the banking law, and perfects the interest rate liberalization content for the purpose of further promoting the development of financial innovation. Thus, American government is hard to regulate the financial market.

(2) Non-strict credit rating

The continuous prosperity of US real estate market promotes the production of massive house loan financial products, continuous decrease of house loan standard and gradual rise of subprime loan proportion. In this process, the market liquidity and the blind investment of investors for the purpose of getting profits increase. These factors promote the production and development of securitized products, but it is hard to evaluate and forecast the securitized products due to the the acquisition of massive loan in a short time, in which the risk coefficient increases. The evaluation reference standard of derivatives in the financial market of credit rating unit is relatively lagged and conservative, in which investors and relevant regulation units have high compliance wit the rating service, leading to the misguidance of credit evaluation to the investors. Thus, investors lose the risk control ability of securitized products and unilaterally form protection with the evaluation unit. The investors also think it can maximize the profits of products, giving rise to the development of fictitious economy and inflation and the inflation effect is seriously far from the development speed of real economy. This causes greater potential risk factors and gives rise to the financial crisis finally.

\section{Conclusion}

In conclusion, the essential cause for the international financial crisis is the performance of the system crisis of capitalism and the relevant remedial measures of western countries can not rectify the system essentially, but just relieve the crisis superficially. Therefore, it is not an economic crisis, but also a profound crisis of the political system of capitalism. The financial crisis imposes serious influences on the economic development of countries all over the world and brings deep impacts to the global culture and ideological field. The international economic situation has far-reaching influences on the international financial crisis. Therefore, the analysis with regard to this is favorable to promote the comprehensive development and construction of socialism with Chinese characteristics.

\section{References}

[1] Gao Fei. Influence of Financial Crisis on China's Economics \& Finance and Enlightenment. China Financialyst, 2012(7),15

[2] Ren Ping. Contemporary Enlightenment of dialectical perspective of Marx's Criticism of Capital - Philosophical Reflection on Global Financial Crisis. Philosophical Trends, 2011(4),26 
[3] Li Yubai. Influence of International Financial Crisis and Enlightenment on Development of China’s Capital Market. Marxism \& Reality, 2013(6),10

[4] Ren Ping. On Contemporary Way of Expression of Marxism. Journal of University of Science and Technology of Suzhou (Social Science), 2011(5),15

[5] Yang Chengxun. Basic Principle of China's Financial System-Deep Lessons from International Financial Crisis. Studies on Mao-Zedong and Deng-Xiaoping Theories, 2012(12),31

[6] Zhang Xiangping. Implementation of Forty Trillion Yuan Expansive Fiscal Policy and Its Influence. Journal of Beijing College of Politics and Law, 2011(3),15

[7] Wang Shubai. Influence of Global Financial Crisis on China and Countermeasures - Interview of WPAS Academician and Economist Zhang Sai. China High-Tech Enterprises, 2012(1),1 